\title{
TEXTO DIGITAL
}

Revista de Literatura, Linguística, Educação e Artes

\section{Fluxos rizomáticos: potencialidades e limites para a circulação, apropriação e criação cultural}

\author{
Rhizomatic flows: potentiality and limits for circulation, \\ appropriation and cultural creation
}

\author{
Marco Antonio de Almeida ${ }^{a}$ \\ a Universidade de São Paulo, São Paulo, São Paulo, Brasil - marcko@uol.com.br
}

Palavras-chave:

Leitura. Consumo Cultural. Cultura da Convergência. Internet. Algoritmos.

Keywords: Reading. Cultural Consumption. Convergence Culture. Internet. Algorithms.
Resumo: O texto é um ensaio que busca refletir sobre aspectos relativos à produção, circulação e apropriação de conteúdos culturais no mundo contemporâneo. Inicialmente, apresenta as concepções de dois autores que marcaram uma inflexão nos estudos acerca dos processos culturais por defenderem o protagonismo dos leitores/consumidores: Michel de Certeau e Henry Jenkins. A seguir, desenvolve aspectos relacionados aos desafios que esse tipo de protagonismo cultural tem que enfrentar no contexto sociotécnico contemporâneo, relacionados aos conceitos de "cultura da convergência" e "cultura do algoritmo", permeados por aspectos relativos às características simultaneamente globais e locais da internet. Conclui apontando o caráter político desses processos, considerando a internet como o campo mais recente das lutas culturais.

Abstract: The text is an essay that seeks to reflect on aspects related to the production, circulation and appropriation of cultural contents in the contemporary world. Initially it presents the conceptions of two authors who marked an inflection in the studies about cultural processes for defending the protagonism of the readers/consumers: Michel de Certeau and Henry Jenkins. Next, it develops aspects related to the challenges that this type of cultural protagonism has to face in the contemporary socio-technical context, related to the concepts of "culture of convergence" and "culture of the algorithm", permeated by aspects related to the simultaneously global and local characteristics of the internet. It concludes by pointing out the political character of these processes, considering the internet as the most recent field of cultural struggles. 


\section{Introdução}

A ideia de literatura como uma grande rede comunicativa, de circulação de conteúdos continuamente apropriados e modificados, não é nova. $\mathrm{O}$ crítico literário norte-americano Harold Bloom, por exemplo, cunhou a expressão "angústia da influência" para construir uma análise da poesia através de uma descrição da influência que se estabeleceu entre autores por meio de uma história das relações intrapoéticas. Desse modo, a história da poesia seria indistinguível da influência poética, já que os grandes poetas fazem a história relendo e "des-lendo-se" uns aos outros, para a partir daí criar seu espaço próprio de fabulação (BLOOM, 1991). Jorge Luis Borges propõe o mesmo em relação à prosa, tanto em suas reflexões críticas como no seu próprio fazer literário - um exemplo disso é o conhecido conto "Pierre Menard, autor do Quixote", onde relata a história de um autor que busca re-escrever a obra de Cervantes a partir do contexto contemporâneo. Reflete Menard, o fictício autor borgiano:

\footnotetext{
Pensar, analisar, inventar [escreveu-me também] não são atos anômalos, são a respiração normal da inteligência. Glorificar o ocasional cumprimento dessa função, entesourar antigos e alheios pensamentos, recordar com incrédula estupefação o que o doctor universalis pensou, é confessar nossa languidez ou nossa barbárie. Todo homem deve ser capaz de todas as ideias e entendo que no futuro será. (BORGES, 2007, p.44)
}

O futuro antevisto por Menard ainda na década de 1940 do século XX parece ter se consolidado nessas primeiras décadas do século XXI. Em certo sentido, seria uma dinâmica do processo cultural que durante muito tempo possuiu caráter emergente ou até residual, mas que agora configura-se como a dinâmica cultural dominante, utilizando as distinções de Raymond Williams (1979). Nesse processo cultural contemporâneo, algumas características merecem ser assinaladas, como o borramento de fronteiras entre campos/territórios culturais, bem como a circulação de conteúdos, linguagens e formas entre "alta", "média" e "baixa" cultura, a presença da tecnologia na produção, disseminação e assimilação da cultura - vide, por exemplo, Eco, 1989; Harvey, 1992; Jenkins, 2009. O que cada um destes autores buscava desmontar, a seu modo, era a imagem de um leitor (ou consumidor cultural) necessariamente "passivo", apontando as possibilidades de leituras alternativas, no limite até oposicionais, mostrando os aspectos ativos e criativos da leitura e, por extensão, da apropriação cultural. 
Cabe assim ecoar a questão levantada por Deleuze e Guattari (1995, p. 3): "Mas a única questão, quando se escreve, é saber com que outra máquina a máquina literária pode estar ligada, e deve ser ligada, para funcionar.” A observação de Deleuze \& Guattari parte de uma concepção de literatura como um vasto agenciamento, uma rede rizomática na qual circulam informações e na qual se processa uma multiplicidade de trocas e influências resultantes de muitos segmentos e estratos, de "linhas de fuga e intensidades, agenciamentos maquínicos e seus diferentes tipos, os corpos sem órgãos e sua construção, sua seleção, o plano de consistência, as unidades de medida em cada caso." (DELEUZE; GUATTARI, 1995, p. 3). A partir da questão dessas observações, outras questões podem ser vislumbradas: como se dá a circulação de conteúdos nessa rede rizomática? Como os sujeitos se perdem e/ou se encontram nesse labirinto? Quais as fronteiras e contingências que envolvem esse deambular? Quais os limites para os "agenciamentos", entendidos aqui como apropriação cultural dos conteúdos pelos sujeitos?

Nesse texto buscaremos apontar algumas referências teóricas para compreender o substrato do processo cultural por trás desses fenômenos, suas potencialidades e limitações, partindo inicialmente de reflexões selecionadas de Michel de Certeau e Henry Jenkins, para em seguida problematizar alguns aspectos do contexto sociotécnico contemporâneo, que envolvem desde presença dos filtros invisíveis relacionados à "cultura do algoritmo", passando por aspectos relativos às características "glocais" da internet.

\section{Do bricoleur ao invasor de texto}

Para refletir acerca desse quadro de discussões, nosso interesse direciona-se para o estudo das relações entre práticas e bens culturais - as formas pelas quais os sujeitos se apropriam destes últimos, e a maneira pela qual essas práticas são influenciadas historicamente pela circulação da informação e pela presença das tecnologias no processo histórico. No que tange especificamente ao longo processo histórico de desenvolvimento, mudança e enraizamento social das tecnologias e meios de comunicação, a obra de Briggs e Burke (2004) nos dá testemunho dos cinco séculos desse processo no Ocidente. Interessa-nos mais de perto analisar a dinâmica sociocultural por detrás desse fenômeno, e aqui o nome de Michel de Certeau merece destaque. 
Em sua influente obra $A$ invenção do cotidiano, publicada originalmente na França em 1980, Certeau desenvolve uma concepção que pressupõe um consumo cultural ativo por parte dos sujeitos, indo na contracorrente das teorias que advogavam que os públicos sempre seriam modelados pelos produtos que lhes eram impostos. Ele critica essas correntes teóricas por entenderem que a assimilação dos bens culturais pelos sujeitos significaria necessariamente que eles tornar-se-iam iguais àquilo que estavam absorvendo, e não que eles tornariam esses bens iguais àquilo que eles eram - que tomariam esses bens culturais como próprios, que se apropriariam deles. No desenvolvimento desse raciocínio, Certeau coloca as atividades de escritura-leitura como centrais, postulando que toda leitura modifica em alguma medida o seu objeto (embora reconheça que a autonomia do leitor esteja condicionada por uma série de relações sociais). Recorre a uma comparação com o modelo de bricolagem proposto por LéviStrauss, ou seja, um arranjo feito com o que se tem à mão, uma produção não relacionada com um projeto pré-existente, que reajusta os resíduos de construções e destruições anteriores.

Subsumido à figura do bricoleur, esse leitor-escritor/consumidor cultural operaria esse processo de apropriação cultural por meio de estratégias (vinculadas à existência de um lugar próprio, circunscrito, apto a servir de base para gerir as relações de força) ou de táticas (ações de "guerrilha", desvinculadas de um lugar próprio, uma arte de aproveitamento das circunstâncias). Numa definição que se tornou bastante conhecida, observa Certeau:

Longe de serem escritores, fundadores de um lugar próprio, herdeiros dos servos de antigamente mas agora trabalhando no solo da linguagem, cavadores de poços e construtores de casas, os leitores são viajantes; circulam nas terras alheias, nômades caçando por conta própria através dos campos que não escreveram, arrebatando os bens do Egito para usufruí-los. A escritura acumula, estoca, resiste ao tempo pelo estabelecimento de um lugar e multiplica sua produção pelo expansionismo da reprodução. A leitura não tem garantias contra o desgaste do tempo (a gente se esquece e esquece), ela não conserva ou conserva mal a sua posse, e cada um dos lugares por onde ela passa é repetição do paraíso perdido. (CERTEAU, 1994, p. 269-270)

A ideia de uma "cultura da convergência", foi desenvolvida paulatinamente por Henry Jenkins a partir da incorporação e modificação das ideias de Certeau, relativas às dinâmicas culturais e sociais, pensando especialmente na maneira pela qual indivíduos e grupos se relacionam com os conteúdos culturais na sociedade contemporânea. A 
primeira aproximação veio com Invasores do texto: fãs e cultura participativa, obra publicada originalmente em 1992, momento marcado pelo declínio dos fanzines impressos e início das primeiras redes digitais, apenas sugeridas nas margens desse texto (JENKINS, 2014). Nesse livro ele parte da analogia de Certeau acerca dos leitores como invasores de terras para cunhar o termo "invasores de texto" (textual poachers no original em inglês) para descrever o comportamento dos fãs da indústria cultural, lançando as bases dos estudos de fandom ${ }^{1}$ que prosperariam nas décadas seguintes. A conclusão a que chega pode soar singela para os dias de hoje, mas foi capital no início dos anos 90: a de que a cultura do fandom não provava que todos os públicos eram ativos, mas que comprovava que nem todas as audiências eram passivas. Faltava a Jenkins, naquele momento, conceitos que ainda estavam em desenvolvimento tanto do ponto de vista teórico como prático, como os de "redes sociais" e de "inteligência coletiva", que seriam capitais para o posterior desenvolvimento de suas ideias. Gradativamente ele vai deixando o conceito de "invasores de texto" de lado, preferindo a ideia de cultura participativa que irá desenvolver na obra Cultura da convergência, lançada em 2006.

Nesse livro ele defende que vivemos um momento de colisão entre novas e velhas mídias, entre produtores e receptores, relacionando três conceitos. O primeiro é a própria ideia de convergência dos meios de comunicação, considerada na perspectiva mais propriamente técnica, a partir da emergência e consolidação da tecnologia digital e das possibilidades de conversão de conteúdos e linguagens distintas em arquivos informacionais. O segundo conceito seria o de cultura participativa, envolvendo trocas e colaborações entre os atores/consumidores, potencializadas graças às características interativas dos novos meios. E, finalmente, a ideia de inteligência coletiva, apropriada de Pierre Lévy².

Jenkins, no entanto, afasta-se de uma visão puramente ufanista ou que considere apenas o papel da tecnologia nas mudanças sociais, ao afirmar que "a convergência não ocorre por meio de aparelhos, por mais sofisticados que venham a ser. A convergência ocorre dentro do cérebro de consumidores individuais e em suas interações sociais com os

\footnotetext{
${ }^{1}$ Por cultura de fandom entende-se um tipo de cultura envolvendo produtos, hábitos e rituais de troca ativamente produzidos, em geral de forma colaborativa, por fãs e outros amadores para a circulação em circuitos de nicho e/ou underground, e cuja maior parte do conteúdo é extraída da cultura comercial vigente. 2 Para Pierre Lévy, a inteligência coletiva implicaria no "estabelecimento de uma sinergia entre competências, recursos e projetos, a construção e manutenção dinâmicas de memória em comum, a ativação de modos de cooperação flexíveis e transversais, a distribuição coordenada dos centros de decisão", tudo isso em oposição aos modelos que preconizavam a "separação estanque entre as atividades, às compartimentalizações, à opacidade da organização social” (LÉVY, 1999, p. 28)
} 
outros" (JENKINS, 2009, p. 30). Ele também aponta que diferenças entre os meios de comunicação muitas vezes são decorrentes de decisões políticas, muito mais que frutos de características tecnológicas propriamente ditas, determinando assim mudanças no contexto comunicacional, ao afirmar que a digitalização estabeleceu as condições para a convergência, mas que foram os conglomerados corporativos que criaram o seu imperativo.

Nessa obra ele incorpora um modelo de mídia em dois níveis, proposto pela pesquisadora estadunidense Lisa Gitelman, que compreenderia um $1^{\circ}$ nível propriamente "técnico", composto pelos meios de comunicação, e um $2^{\circ}$ nível, configurado pelo conjunto de protocolos associados às práticas sociais/culturais. Esse modelo considera que meios novos não substituem ou eliminam pura e simplesmente os antigos (na verdade, reconfiguram seus lugares no ecossistema da mídia). A convergência envolveria, desse modo, uma transformação não só na forma de produzir, como também nas formas de “consumir" os meios de comunicação. O foco maior, portanto, seria nas mudanças de "protocolos", mais que nas mudanças de tecnologia em si.

A convergência permite aos "usuários" novas formas de controlar seu acesso às mídias e seus conteúdos, bem como produzir e distribuir outros conteúdos produzidos por eles com resultados criativos ou catastróficos. A convergência se aproximaria assim, nas próprias palavras de Jenkins, de uma sucessão de "gambiarras": "num futuro próximo, a convergência será uma espécie de gambiarra - uma amarração improvisada entre as diferentes tecnologias midiáticas - em vez de um sistema completamente integrado." (JENKINS, 2009, p. 45). Nesse sentido é que ele aponta a emergência da figura do prosumer (neologismo oriundo da combinação das palavras produtor e consumidor). A concepção do prosumer parte da constatação de que, potencialmente, os indivíduos na sociedade em rede tornaram-se capazes, com as ferramentas disponíveis, de tornarem-se produtores de conteúdo, num processo dialógico envolvendo os conteúdos simbólicos e outros sujeitos. Essa possibilidade estabeleceria um ciclo contínuo entre os papéis de emissores/receptores das mensagens, conferindo-lhes, então, a simultaneidade entre produção e consumo - embaralhando, consideravelmente, o que tradicionalmente compreendemos como "usuários", "consumidores" ou "público". 
O perfil do prosumer sucede ao de "invasor de texto", realçando o papel ativo das audiências/públicos, que foi tornando-se cada vez mais comum, com uma forte contribuição das mídias sociais no processo. Esse processo também se relaciona com a ampliação do que Chris Anderson (2006) descreve como "cauda longa" da indústria cultural. Esse fenômeno implica na crescente possibilidade de as pessoas encontrarem ofertas culturais minoritárias que seriam de seu interesse, mas que em geral não são providas pela indústria de entretenimento - possibilitando, muitas vezes, a emergência de verdadeiras culturas de "nicho". Assim, no cenário contemporâneo se observariam dois movimentos e/ou processos concomitantes: de um lado, ampliação das possibilidades de os consumidores/internautas acessarem, apropriarem e modificarem conteúdos culturais; de outro lado, o aumento exponencial da concentração de propriedade dos meios de comunicação comerciais, formando grandes conglomerados. Questão: rumamos para um mundo com mais ou menos "controladores" dos fluxos de informação e conhecimento, com maior ou menor acesso aos conteúdos culturais?

\section{Há minotauros no labirinto}

A diversidade de conteúdos e formatos disponíveis nas redes infocomunicacionais, aliadas às possibilidades abertas pelo formato digital para sua manipulação e reconfiguração permitem a hibridização e a recriação cultural por parte dos indivíduos e grupos, gerando distintas possibilidades de apropriação cultural no âmbito de uma cultura da convergência. Entretanto, embora a ideia de uma cultura da convergência seja pertinente como descrição de um processo cultural global envolvendo a apropriação cultural mediada pelas tecnologias, características e condições decorrentes não só das características propriamente técnicas dos aparatos, como também especificidades locais - culturais, sociais, políticas - influenciam essa dinâmica. (ALMEIDA, 2016)

De um modo geral, a ideia de rede vislumbra um universo de liberdade e abundância informacional ao alcance dos indivíduos e grupos, apoiada na ideia de "neutralidade" das tecnologias. Trata-se de uma mistificação baseada numa premissa falsa. Não existe uma rede sociotécnica sem escolha, sem organização, sem hierarquia: tanto as informações como os conhecimentos existem apenas inseridos em um contexto social. Esse contexto demanda um conjunto de competências críticas - comunicativas, culturais, educacionais e cognitivas - que são imprescindíveis para indivíduos contextualizarem e utilizarem as 
informações e conhecimentos que aí circulam. É nessa perspectiva que faz sentido um breve esclarecimento crítico acerca dos processos de mediação algorítmica da chamada Sociedade da Informação.

O termo algoritmo designa, de forma geral, uma instrução ou conjunto de instruções (um método, enfim) para se resolver um problema ou se chegar a um resultado pretendido de forma efetiva. Define, assim, toda tomada de decisão passível de ser expressa em linguagem matemática. O exemplo comumente associado à explicação do funcionamento de um algoritmo é o da receita de bolo: conjunto de informações referentes à quantidade de ingredientes e ao método de preparo, implicando em seguir as instruções para se obter um bolo adequado. Os algoritmos e as técnicas de aprendizado de máquina distribuídos pelas plataformas que acessamos na internet operam de maneira semelhante, criando "receitas" a partir de informações sobre nossas preferências para prever o que será de nosso interesse.

Essa definição passa por cima, entretanto, de aspectos cruciais acerca da natureza dos algoritmos. O primeiro aspecto é deduzir do fato dos algoritmos serem fórmulas matemáticas sua suposta "neutralidade" - vale lembrar que o algoritmo é composto por uma série de decisões humanas, um conjunto de operações e métodos definidos como os mais eficazes para se chegar aos objetivos definidos. Se o objetivo for o lucro das empresas, algoritmos e técnicas de filtragem de conteúdo informativo e publicitário serão projetados para utilizar o comportamento prévio das pessoas na rede para prever os tipos de conteúdo mais atrativos, com potencial para produzir um maior tempo de permanência e engajamento dos indivíduos na rede.

Aí reside um outro aspecto problemático, muitas vezes desconsiderado pelo senso comum e até mesmo no ambiente acadêmico, de que os algoritmos mostram o que, de fato, as pessoas querem ver. Considerando que algoritmos construídos para oferecer conteúdos personalizados compreendem uma notícia que não foi lida ou um vídeo ou música não vistos como fracasso, e um like ("curtida") em uma foto ou um comentário postado como sucesso, a tendência é que vejamos mais vídeos, fotos e textos de pessoas ou sobre assuntos pelos quais demonstramos interesse em nossas interações e engajamentos prévios (vale lembrar que Apple, Microsoft, Google, Amazon, Facebook, Netflix e Spotify 
não são organizações sem fins lucrativos, mas multinacionais capitalistas que têm como objetivo o lucro, cujos algoritmos são privados e confidenciais ${ }^{3}$ ).

A concepção de uma "cultura dos algoritmos" baseia-se numa metáfora construída a partir do fenômeno da explosão dos dados, o Big Data, e procurar dar conta de suas consequências para o debate não apenas da tecnologia, mas também da cultura, da economia e da política contemporânea, quando decisões tomadas de forma automática por parte de aplicativos disseminam-se pelo mundo todo. Esta imagem penetrou e enraizou-se nas discussões cotidianas, construindo uma paisagem no imaginário social constituída por "reservatórios de dados", estoques de informação dos usuários, minas a serem exploradas, num paralelo com o extrativismo dos recursos naturais. Essa concepção de dados como "recursos" tornou-se corriqueira, embora sua produção seja muito diferente de como a Natureza produz seus recursos. Os conglomerados tecnológicos, e mesmo as empresas menores, concentram seus esforços publicitários no "compartilhamento" - a cessão voluntária dessas informações por parte das pessoas, primeira etapa para a construção de uma utopia comunitária de melhores serviços, de construção de conhecimentos e de partilha de "experiências". Desse modo, o verdadeiro pecado capital dos tempos correntes é não compartilhar dados.

Entretanto, como observa Evgeny Morozov (2018), este “extrativismo de dados" possui consequências econômicas, políticas e socioculturais ${ }^{4}$. Um exemplo dado por Morozov, que nos interessa mais de perto, é o da penetração dessa "cultura dos algoritmos" que está na disseminação das fake news. As notícias falsas são difundidas há muito tempo, porém agora elas circulam no meio digital com muita maior facilidade e velocidade pelo fato de se adequarem bem aos modelos de negócio baseados em cliques, fundamentados na lógica do extrativismo de dados. Na medida em que essa lógica já foi naturalizada pelo

\footnotetext{
${ }^{3}$ Em 2019, por exemplo, mudanças nos mecanismos de busca da Amazon geraram a suspeita de que a empresa estaria artificialmente impulsionando seus produtos, colocando em xeque o argumento utilizado pela empresa com seus usuários: de que as pessoas que compravam determinados livros também compravam as demais sugestões feitas pela plataforma.

${ }^{4}$ No campo econômico, vemos riquezas imensas sendo acumuladas por um punhado de investidores e gigantes empresariais. No setor público, a reforma de grandes sistemas, como os de saúde, educação, administração pública ou previdência envolve a intermediação dos provedores de serviços digitais, acenando com a economia de recursos, mas com a contrapartida (quase nunca discutida), de perda de controle político e de governabilidade sobre decisões que passaram a serem exercidas "tecnicamente" pelos algoritmos. Como alerta Morozov, "deveríamos fazer um balanço dos fatores estruturais que levam os governos e outras instituições públicas às mãos dessas grandes empresas de tecnologia" (MOROZOV, 2018, p. 168).
} 
senso comum, a forma de reação à disseminação das fake news acaba por reforçar a confiança nas grandes empresas de tecnologia, atribuindo-lhes o papel de identificar e distinguir o que é falso do que é verdadeiro. O paradoxo consiste em que elas só poderiam realizar essa operação por meio de algoritmos, um processo no qual já demonstraram particular incompetência - basta lembrar os recorrentes casos equivocados de distinção entre fotos artísticas e fotos pornográficas realizadas pelo Facebook. As expectativas depositadas sobre esse controle algorítmico "neutro" politicamente imposto "é parte de um esforço maior de recrutamento de tecnologias preditivas - aproveitando o enorme volume de dados já acumulados - em nome do controle e da vigilância" (MOROZOV, 2018, p. 170).

Essa característica dos algoritmos reforça o argumento de Eli Pariser (2012), para quem a informação que consumimos agora nem sempre é a informação que realmente queremos ou que julgamos melhor para nós. Para dar conta desse fenômeno popularizou o termo "filtro bolha" (filter bubble), ou filtros invisíveis - o conjunto de mediações que filtra as informações que chegam até nós, baseadas em princípio por nossas preferências e interações e controlado pelos algoritmos. Apesar de reconhecer algumas das vantagens desse formato de internet, sua preocupação reside no fato de que esse processo é invisível para os usuários e totalmente fora de controle: “(...) a internet talvez saiba quem somos, mas nós não sabemos quem ela pensa que somos, ou como está usando essas informações" (PARISER, 2012, p. 193). A tecnologia que deveria nos proporcionar mais controle sobre nossas vidas, aos poucos, está retirando-o. Ele argumenta que o ideal seria uma busca de equilíbrio entre conteúdos familiares e conteúdos que alimentem nosso cérebro, nossa criatividade, e que nos permitam ter uma visão de mundo mais permeada pela diversidade de opiniões e pontos de vista, para não nos encastelarmos em nosso universos autocentrados - processo para o qual contribui a própria arquitetura de muitas redes sociais.

Nesse sentido, os artistas e produtores dos projetos são reféns dos algoritmos, que refletem quem é mais visto e quem possui mais chances de ser "visualizado" - e os indivíduos, por sua vez, são fortemente encorajados e direcionados a ver o que "todo mundo" está vendo. Este aspecto se acentua quando se associam os projetos às redes sociais - notadamente o Facebook - para sua divulgação. Nesse ponto, o efeito de "bolha de filtros" passa a influenciar o alcance da divulgação dos projetos. Essa tendência ao 
encapsulamento seria até de se esperar, numa "cultura de nicho", retomando Anderson (2006), mas atualmente isso é ainda mais acentuado e encorajado pelas próprias empresas que gerem essas redes sociais, como, por exemplo, a política de pagamento para impulsionar postagens, promovida pelo Facebook. Ainda que a ideologia propagandeada seja a de que "o público escolhe o que quer", a ação dos algoritmos trabalha, em realidade, no sentido de que o público escolha aquilo que lhe é apresentado.

Por outro lado, podemos radicalizar o argumento de Anderson, no sentido de compreender a internet como sendo, na verdade, um conjunto de culturas paralelas ${ }^{5}$. As observações de Frédéric Martel (2015) apontam nessa direção. Para ele, as conversas e conexões propiciadas pela internet tendem a ser muito mais delimitadas por "comunidades" cultural e geograficamente delimitadas, raramente se revelando globais. Ele recorda que a expressão "comunidade" (community) não está necessariamente vinculada a um território específico, podendo remeter ao mesmo tempo a um grupo étnico, uma minoria sexual, uma religião ou a um bairro: “às vezes, esse 'território' assume uma forma linguística ou cultural; reflete então uma comunidade unida por interesses, afinidades ou gostos" (MARTEL, 2015, p. 417). Embora o tráfego de informações seja potencialmente global, possibilitado por ferramentas e aplicativos predominantemente de origem estadunidense, as conexões seriam majoritariamente locais, apoiada em fatores como a produção de conteúdos nas línguas locais e nacionais, assim como o surgimento de aplicativos e serviços voltados para as especificidades culturais de cada comunidade.

Martel explora em seu livro o papel dos Estados na configuração de diferentes tipos e formas de utilização da internet, analisando situações, entre outras, na China, no Irã, no México, na Índia, no Japão e no Brasil. O painel diversificado que emerge de sua análise proporciona diversos subsídios para se refletir acerca do papel dos governos e sua relação com os cidadãos, com todas as contradições daí decorrentes. O desafio dos Estados no cenário das redes digitais tornou-se bastante ambíguo: não podem ignorá-las, mas ao mesmo tempo não podem se deixar capturar por elas. O desafio se estende aos cidadãos, que percebem sua impotência diante dos mecanismos invisíveis que governam as redes. As revelações como as do WikiLeaks, de Julian Assange, ou aquelas proporcionadas por Edward Snowden, repercutem e constroem, por sua vez, uma imagem cada vez menos

\footnotetext{
${ }^{5}$ A partir daqui retomaremos resumidamente o raciocínio desenvolvido em Almeida, 2016.
} 
idílica da internet, que afeta a governabilidade dos Estados e o cotidiano dos cidadãos: "A realidade das relações de força mudou. O governo dos algoritmos entra em competição com o governo dos Estados”. (MARTEL, 2015, p. 444)

Em seu trabalho, Martel desenvolve as implicações do conceito, trabalhado por outros autores, de glocal (global + local), apresentando a internet como uma rede federalizada, de infraestrutura global e desterritorializada, mas com conteúdos majoritariamente territorializados. Entretanto, em alguns setores essa tendência de territorialização não se confirma totalmente, caso dos entretenimentos de massa em geral, particularmente do cinema e dos videojogos. Nesses segmentos específicos, a internet e o mainstream se complementam, participando de um mesmo movimento de eliminação de fronteiras e globalização de conteúdos visando a um público mais "global". Essa tendência não possui uma força correspondente nos setores da televisão, da música, dos livros, ainda fortemente ancorados nas especificidades culturais locais. Martel não nega, portanto, a existência de uma internet mainstream global, de conteúdos e fluxos padronizados culturalmente, mas procura apontar "que esses conteúdos muitas vezes são superficiais e quantitativamente limitados. Além dos fluxos americanizados, existem numerosos outros streams" (MARTEL, 2015, p. 431).

A partir da perspectiva de Martel podemos retomar algumas considerações de Jenkins, refletindo acerca da reprodução de alguns fenômenos que ele descreveu no âmbito estadunidense, só que em contextos culturais distintos, observando assim "manifestações culturais híbridas, que vão da tentativa de reprodução mais próxima possível do original, com apenas a tradução para o idioma local, até apropriações mais livres ou transgressivas, incorporando traços culturais distintos" (ALMEIDA, 2016, p. 155). As apropriações e hibridizações dessa circulação acelerada de formas e processos culturais, manifestam-se tanto em conteúdos como em formatos. Comunidades de fãs de Star Wars, Harry Potter ou de Star Trek são encontradas em diversas partes do mundo, realizando convenções, intercambiando informações e opiniões em sites e redes sociais, produzindo textos e vídeos a partir dessas produções originais. Do mesmo modo, canais e redes de televisão locais e regionais adaptam os formatos hollywoodianos a seus contextos culturais, produzindo versões locais de programas como American Idol (música), Big Brother (reality shows) ou se apropriando de gêneros audiovisuais conhecidos - sitcoms, dramas históricos, seriados policiais e até narrativas de ficção científica. O fenômeno vai 
tornando-se mais simbiótico, com o preenchimento da grade de redes internacionais de streaming como Netflix e Amazon Prime como produções locais - do Brasil à Coréia, passando por México, Argentina, Turquia, Índia, entre outros países. A contrapartida desse cenário reside no aumento do grau de dificuldade para a veiculação de conteúdos com menor "visibilidade". Esses conteúdos podem não encontrar espaço, deixando de ser produzidos ou restringindo-se à circulação exclusivamente local.

Podemos exemplificar com alguns conteúdos locais relacionados às culturas indígenas no Brasil, que buscaram diferentes formas de expressão nos mais diversos formatos:

Próximo à Dourados (MS), o grupo Brô MC's, formado por adolescentes indígenas canta raps na língua guarani, tematizando a vida na aldeia e sua relação com a sociedade mais ampla - e já preparam o segundo disco. No Acre, uma parceria entre indígenas e não-indígenas, em uma equipe que reuniu programadores, artistas e antropólogos e pessoas da comunidade Huni Kuin, criou um videogame com a história desse grupo. O projeto se chama "Huni Kuin: os caminhos da jiboia", consistindo em um jogo de plataforma de cinco fases, onde cada fase conta uma antiga história desse povo. No Pará, a TV Cultura local, por meio de um concurso de audiovisual, viabilizou a produção de curtos episódios de animação protagonizados por quatro indígenas superpoderosas, uma mistura de desenho de heroínas com a cultura do Norte do país, baseando-se na lenda das icamiabas, amazonas que viviam em uma comunidade sem homens. O projeto agrega situações cotidianas, contemporâneas, bem como sotaques e termos típicos regionais. (ALMEIDA, 2016, p. 156)

Existem exemplos semelhantes nos demais países latinos, como o Zambo Dendê, na Colômbia, que narra a saga de um guerreiro que luta para libertar os escravos dos conquistadores portugueses e espanhóis na América Latina da época da colonização. Surgido inicialmente nas histórias em quadrinhos, o personagem tornou-se animação e série de TV, e escapando da órbita local, seus direitos estavam em negociação para adaptação/distribuição nos EUA.

Em trabalho anterior enfocando a produção, circulação e apropriação cultural no universo das histórias em quadrinhos, observamos que esse mercado encontrou formas de se desenvolver mesmo com todas as dificuldades em relação à publicação física e o alto custo de se criar um trabalho artístico moldando-se, em larga medida, às práticas culturais de seu público (ALMEIDA, 2018). O contexto cultural do fandom, que vinculava os fãs entre si e com a indústria cultural, não foi abandonado na transição para o universo digital, sendo remodelado e adaptado às novas possibilidades abertas pelas tecnologias. As 
possibilidades abertas pelas redes sociais, bem como o uso das tecnologias digitais, contribuiu fortemente para esse resultado, ao reconfigurar as relações entre produtores/consumidores de produtos e informações culturais ligadas às HQs, remetendo à relação entre estratégias e táticas de apropriação e consumo tais como as preconizadas por Michel de Certeau (1994) ${ }^{6}$.Com as práticas hipermediadas de participação e uso colaborativo de ferramentas digitais por parte das subculturas do meio, o mundo das HQs teve seu entorno comunicacional modificado.

O exemplo acima permite visualizar como essas práticas desenvolvidas no âmbito das culturas de nicho permitem inferir novos hábitos culturais expressos em práticas culturais "marginais", estratégias e táticas de apropriação relacionadas às formas de colaboração horizontal proporcionadas pelas tecnologias interativas em rede. A multiplicação dessas conexões contribui para legitimar paulatinamente essas práticas culturais, configurando e legitimando os atos de recepção como atos de produção cultural, na perspectiva de constituição dos prosumers, segundo Jenkins (2009), constituindo reservatórios de conteúdos diferenciados e incentivado o surgimento de novas vozes autorais.

Por outro lado, vale lembrar as práticas de "monetização" dos conteúdos culturais criados nas redes. As indústrias culturais e seus grandes conglomerados encontraram na rede um manancial de novos conteúdos e artistas que nela despontam, e que são rapidamente atraídos e absorvidos pelo mainstream. Dos exemplos já sobejamente conhecidos de escritoras como Stephenie Meyer (da saga Crepúsculo) e E. L. James (da saga 50 Tons de Cinza), passando pelos novos youtubers incorporados pelos canais de TV a cabo e desembocando nos ídolos do funk e do rap que surgem a cada semana dos rincões da internet, essa dinâmica de retroalimentação entre a rede e as indústrias culturais tornouse um processo consolidado. Nesse sentido, a mediação algorítmica tende a priorizar algumas modalidades de criação artística e cultural, de leitura legitimadas pelo status quo ou por consensos expressos por uma perspectiva quantitativa, em detrimento de outras produções mais diferenciadas ou disruptivas.

\footnotetext{
${ }^{6}$ A cultura do scan consolidou-se como um conjunto de práticas que iam além da noção simplória de "pirataria", constituindo-se como um repertório de processos que norteavam as escolhas dos públicos no que dizia respeito ao acesso, seleção, leitura e mesmo aquisição comercial das produções. Essa cultura adquiriu um formato próprio, sustentado pela disseminação de formatos digitais como Comic Book Archive File e ferramentas como o CDisplay, consolidando novos padrões de interação e colaboração que acabaram por influenciar a própria indústria cultural sobre a qual incidia a ação dos fãs. (ALMEIDA, 2018)
} 
O sistema cultural do mundo contemporâneo caracteriza-se, cada vez mais, por sua crescente complexidade. Esses breves exemplos de apropriações e hibridizações culturais, de circulação de formatos e conteúdos, demonstram que se trata de processos bem diversificados, envolvendo muitas possibilidades e estratégias. George Yúdice (2006) considera que a cultura no mundo contemporâneo se torna um recurso cada vez mais estratégico - mas problematiza essa discussão não reduzindo-a exclusivamente à lógica do mercado. No presente contexto, os recursos culturais, assim como os naturais, não comportam uma exploração pura e simples. O cenário que se delineia implica em múltiplos desafios, para Estados, corporações, organizações e coletivos, envolvendo conciliar os impulsos locais, nacionais e globais, fomentando a produção, a qualidade, a distribuição, a circulação e a apropriação dessas expressões.

\section{Considerações finais}

Em suas reflexões acerca da cultura de massa na primeira metade dos anos 60, Edgar Morin apontava um aspecto que lhe parecia crucial para o seu entendimento: uma dinâmica interna que compartilhava simultaneamente elementos ambivalentes de reprodução e de inovação (MORIN, 1978). Mais de cinco décadas depois, os conceitos contemporâneos de "cultura da convergência" e de "cultura dos algoritmos" atualizam o paradoxo entrevisto por Morin. Se, por um lado, as facilidades proporcionadas pelas tecnologias digitais e pelas redes sociotécnicas incentivam a produção colaborativa, a criatividade e a circulação de conteúdos diversificados, por outro lado a lógica de filtragem dos algoritmos que tem prevalecido até o momento favorece a circulação de conteúdos já conhecidos, a manutenção de valores do status quo e a apropriação das novas criações pelo capital.

Jenkins assinala que uma das marcas da convergência das mídias tem sido o deslocamento dos conteúdos produzidos e disseminados por uma cultura midiática na direção de outros suportes e de novas perspectivas de acessibilidade mediante o estabelecimento de relações mais complexas entre as interfaces/produtos e a manifestação participativa de suas audiências e das subculturas particulares, das culturas de nicho, para uma ampliação em direção a um modelo que engloba mais grupos que adquirem progressivamente maiores capacidades de comunicação dentro da cultura em rede "e rumo a um contexto 
em que a produção cultural de nicho está cada vez mais influenciando o formato e a direção da mídia mainstream". (JENKINS, GREEN; FORD, 3014, p. 64)

Esse cenário embaralha as perspectivas acerca da adesão ou da resistência cultural, na medida em que os papéis desempenhados pelos diversos atores estão cada vez mais complexamente entrelaçados. Assim, "estamos passando da celebração do crescimento de oportunidades de participação para uma perspectiva ponderada pela atenção aos obstáculos que impedem muitas pessoas de exercer uma participação significativa" (JENKINS, GREEN; FORD, 3014, p. 65).

Vale, no entanto, recordar que uma discussão política fundamental se relaciona à concepção de tecnologia na forma pela qual ela é manipulada hoje pelo setor extrativista de dados. Isso não deve ser confundido com uma crítica da tecnologia em si, mas uma constatação de que a adoção acrítica da ideia de Big Data e da cultura dos algoritmos associada (quanto maior o conjunto de dados, mais verdade se pode extrair deles) contribuiu para uma retomada de perspectivas positivistas e de concepções monolíticas acerca do conhecimento. Uma grande interrogação é como a intensificação do regime de extrativismo de dados, e suas imposições de vigilância e controle, bem como a perda de autonomia política correlatas, ainda não geraram um descontentamento ou uma revolta generalizada. Uma explicação possível reside no canto de sereia propagado pela mitologia originada no Vale do Silício, em torno da neutralidade bondosa da tecnologia e nas potências criadoras do empreendedorismo individual.

Esses fatores são fortes obstáculos à proposição de uma cultura efetivamente colaborativa, dadas as assimetrias que induzem, cerceando os espaços de expressão e criatividade. Torna-se necessário recuperar a dimensão do humano, do social, e reforçar a necessidade do dialogismo, do debate público, de um conjunto de práticas verdadeiramente políticas em contraposição à imposição das visões tecnocráticas. A internet, nesse sentido, e apesar de todos os filtros tecnológicos e ideológicos, tem se configurado, ao mesmo tempo, como a arena e o objeto de disputa mais visível da guerra cultural contemporânea. 


\section{REFERÊNCIAS}

ALMEIDA, Marco Antônio de. Práticas infocomunicacionais e mediações na cultura da convergência. Revista do Centro de Pesquisa e Formação do SESC, São Paulo, n. 7, p. 228-242, 2018.

ALMEIDA, Marco Antônio de. Processos culturais \& Convergências tecnosociais. Revista do Centro de Pesquisa e Formação do SESC. São Paulo: SESC, n. 3, p. 142$158,2016$.

ANDERSON, Chris. Cauda longa: do mercado de massa para o mercado de nicho. Rio de Janeiro: Elsevier, 2006.

BLOOM, Harold. A angústia da influência: uma teoria da poesia. Rio de Janeiro: Imago, 1991.

BORGES, Jorge Luis. Ficções. São Paulo: Companhia das Letras, 2007.

BRIGGS, Asa; BURKE, Peter. Uma história social da mídia: de Gutemberg à Internet. Rio de Janeiro: Jorge Zahar editores, 2004.

CERTEAU, Michel de. A invenção do cotidiano: 1. artes de fazer. Petrópolis: Vozes, 1994.

DELEUZE, Giles; GUATTARI, Félix. Mil Platôs (Capitalismo e Esquizofrenia) Vol. 1. São Paulo: Editora 34, 1995.

ECO, Umberto. Sobre os espelhos e outros ensaios. Rio de Janeiro: Nova Fronteira, 1989.

HARVEY, David. Condição Pós-Moderna. São Paulo: Loyola, 1992.

JENKINS, H. Cultura da convergência. São Paulo: Aleph, 2009.

JENKINS, Henry. Invasores de textos: fãs e cultura participativa. Nova Iguaçu Marsupial, 2015.

JENKINS, H.: GREEN, J.; FORD, S. Cultura da conexão. São Paulo: Aleph, 2014.

LÈVY, Pierre: Cibercultura. São Paulo: Editora 34, 1999. 
MARTEL, Frédéric. Smart: o que você não sabe sobre a internet. Rio de Janeiro:

Civilização Brasileira, 2015.

MORIN, Edgar. Cultura de massa no século XX vol. 1: Neurose. Rio de Janeiro:

Forense Universitária, 1978.

MOROZOV, Evgeny. Big Tech: a ascensão dos dados e a morte da política. São Paulo: Ubu Editora, 2018.

PARISER, Eli. O filtro invisivel: o que a internet está escondendo de você. Rio de Janeiro: Jorge Zahar, 2012.

WILLIAMS, Raymond. Marxismo e literatura. Rio de Janeiro: Zahar, 1979.

YÚDICE, George. A conveniência da cultura: usos da cultura na era global. Belo Horizonte: UFMG, 2006.

YÚDICE, George. Internet en manos de sectores privados hoy está disputando el poder a los Estados. Entrevista a Karina Wroblewski. La Nación, Argentina, 17/05/2015.

Disponível em: http://www.lanacion.com.ar/1792906-internet-hoy-esta-disputando-elpoder-a-los-estados Acesso em 01/06/2015. Acesso em: 20 abr. 2020.

\section{NOTAS DE AUTORIA}

Marco Antonio de Almeida (marcko@uol.com.br) é Doutor em Ciências Sociais, Livre-Docente em Ciência da Informação. Professor do PPGCI-ECA/USP e do Departamento de Educação, Informação e Comunicação da FFCLRP-USP

Como citar este artigo de acordo com as normas da revista?

ALMEIDA, Marco Antonio de. Fluxos rizomáticos: potencialidades e limites para a circulação, apropriação e criação cultural. Texto Digital, Florianópolis, v. 16, n. 1, p. 36-54, 2020.

\section{Contribuição de autoria}

Não se aplica.

\section{Financiamento}

Não se aplica.

Consentimento de uso de imagem

Não se aplica.

Aprovação de comitê de ética em pesquisa

Não se aplica.

\section{Licença de uso}


Este artigo está licenciado sob a Licença Creative Commons CC-BY. Com essa licença você pode compartilhar, adaptar, criar para qualquer fim, desde que atribua a autoria da obra.

\section{Histórico}

Recebido em: 23/03/2020.

Aprovado em: 16/04/2020. 